\title{
Cost-minimizing food budgets in Ghana
}

\author{
Francis Addeah Darko*, Benjamin Allen, John Mazunda, Rafiullah Rahimzai and \\ Craig Dobbins
}

\author{
Department of Agricultural Economics, Purdue University, 403 West State Street, \\ Krannert Bldg.West Lafayette, IN 47907, Indiana, United States.
}

Accepted 16 January, 2013

\begin{abstract}
Attaining the daily required nutritional recommendations is a major challenge in Ghana where the average person earns about $\$ 1.89$ per day. A linear programming diet model is used to determine the cheapest basket of food items that satisfy the recommended daily nutritional requirements of the average Ghanaian. Initial findings show that an average Ghanaian requires \$0.36 per day to meet his daily nutritional needs. This would be met with a food basket made up of sorghum, yam, cassava, coconut and milk. With this food basket and the estimated food expenditure, the average person in Ghana would save about $\mathbf{4 0} \%$ of his/her daily food expenditure. Sensitivity analyses are also performed to test the robustness of the findings.
\end{abstract}

Key words: Developing countries, nutrition, minimum costs, linear programming.

\section{INTRODUCTION}

Economic livelihood is largely dependent on nutrition. Good nutrition promotes growth and development in children, and improves work capacity and productivity of adults directly or indirectly through its concomitant reduced vulnerability to diseases (Smith and Haddad, 2000). That notwithstanding malnutrition, underweight and overweight, remains a major problem in SubSaharan Africa, South Asia and other developing countries. In 1995, about one-third of children aged five and below living in developing countries were undernourished (Smith and Haddad, 2000). Between 2000 and $2002,96 \%$ of the 852 million undernourished people in the world were living in developing countries (Muller and Krawinkel, 2005). Ziraba et al. (2009) also reports that about $30 \%$ of urban dwellers and $10 \%$ of rural dwellers in Africa are either overweight or obese.

Like other developing countries, malnutrition is very prevalent in Ghana. About $14.3 \%$ of children are in Ghana are underweight (CIA, statistics, 2012). A study conducted by DHS-Africa over the period of 2003 to 2007 reported that about $18 \%$ of Ghanaian women are obese. A similar study by Ziraba et al. (2009) observed that about $35 \%$ of urban dwellers and $15 \%$ of rural dwellers in Ghana are either overweight or obese. Anthropometric measures of nutritional status show a strong nutritional pattern, with malnutrition roughly increasing from the southern to the northern part of the country (Alderman, 1990). Given the importance of nutrition to economic livelihood, it is important that the malnutrition problem in Ghana is addressed. The components of food basket in Ghana differ from one ecological zone to another. Whilst roots, tubers and plantains dominate the food basket in the forest and rural coastal zones, grains (millet, sorghum and maize) dominate the food basket of households living in the savannah zone. The difference in the components of zonal food baskets follows a pattern - the average Ghanaian only spends on food items that are not produced in his/her zone of residence. For instance, 
forest and rural coastal zone dwellers produce mainly roots and tubers and virtually nothing of grains. Because they do not produce grains, grains sell at a relatively higher price in the forest and rural coastal zone compared to the savanna zone where they are largely produced.

\section{Problem statement}

The average Ghanaian earns $\$ 1.89$ per day (World Bank, 2008), and depending on the area of residence, spends 61 to $76 \%$ of this income on food. In view of this, although the national food balance sheet (available at FAO statistical database, FAOSTAT) indicates that sufficient food is available, many people resort to eating mainly what they produce, or at least what is produced in their ecological zone of residence, in order to curtail food expenditures. This behavior tends to affect the nutritional status of Ghanaians as the locally produced food items in a particular ecological zone do not frequently make nutritionally excellent diets. Against this background, this study seeks to identify a combination of food items that can be purchased at a minimum cost and at the same time, meet the nutritional requirements of the average Ghanaian.

\section{LITERATURE REVIEW}

The question of obtaining the Recommended Dietary Allowance (RDAs) at the lowest possible cost has been a matter of concern for quite a long time now. Garille and Gass (2001) illustrates that economic literature credits Stigler's (1945) diet problem for its role in present linear programming applications. Stigler's interest was to find how much of his chosen 77 foods would be consumed by a man weighing 154 pounds so that his intake of nine nutrients would be at least equal to the recommended dietary intake (as suggested by the National Research Council) while maintaining minimum costs. Stigler's RDAs of interest were calories, protein, calcium, iron, vitamin $A$, niacin, riboflavin, thiamine and vitamin $C$.

Stigler (1945) argues that no one before his study had attempted to determine the minimum cost of obtaining the amount of calories, protein, minerals, and vitamins which other studies have accepted as adequate or optimum. He argues that a minimum cost of an adequate diet is governed by the nutritive values and the costs of food eligible for inclusion. He reasons that the other conventional diets cost so much because dieticians take account of the palatability of foods, variety of diet, prestige of various foods and other cultural aspects of consumption. Only natural foods were included in his diets since vitamin pills do not contain all the nutrients needed for a man's good health. In his solution, Stigler identified nine food items that minimized costs while providing the required nutrients. His diet consisted of varying amounts of wheat flour, cornmeal, evaporated milk, peanut butter, lard, beef liver, potatoes, spinach and dried navy beans. Garille and Gass (2001) points out the inadequacies of Stigler's minimal subsistence diet in terms of palatability, variety, and overall adequacy. In her article describing the evolution of the diet model into a more acceptable menu-planning approach, Lancaster (1992) observes that "the solution to the least cost diet is the equivalent of the human dog biscuit." The combination of food items may not be desirable for consumption but nutrition and costs are controlled. Darmon et al. (2002) illustrates that Linear Programming is important as it can be utilized to help explain observational studies by modeling underlying structures of food choice, independent of social or cultural factors or the declaration bias inherent to dietary surveys.

\section{MODEL FORMULATION AND DESCRIPTION}

A linear programming model is used to find the cheapest combination of food items that satisfies the most important daily nutritional requirements of a 22 year old Ghanaian male. Linear programming models optimize (minimize or maximize) linear functions of a set of decision variables, while respecting multiple linear constraints (Ferguson et al., 2003). A first step in developing a linear programming model for diet optimization is to establish a clear question that has to be addressed by the model. An objective function that best answers the question must then be formulated and expressed as a linear function of the decision variables. Finally, nutritional and palatability constraints must be identified to govern the diet optimization process (Breind et al., 2003).

According to FAO statistical database (FAOSTAT) the following food items are the most significant in the food balance sheet of Ghana: cassava, yams, plantains, maize, tomato, rice, oranges, sorghum, coconuts, milk, poultry, cattle meat, and pig meat. The model is specified as follows:

Minimize $Z=\sum_{j} C_{j} X_{j}$

Subject to:

$$
\begin{aligned}
& B_{i} \leq \sum_{j} A_{i j} X_{i j} \\
& \sum_{j} S_{i j} X_{i j} \leq K_{i} \\
& X_{j} \geq 0 \\
& \sum_{j} X_{j} \leq 3 K g
\end{aligned}
$$

The objective of the model is to minimize food expenditure, $Z$ (in US $\$$ ). $X_{j}$ is the quantity (in $\mathrm{kg}$ ) of food item, $j ; A_{i j}$ denotes the amount of nutrient $i$, in one kilogram of food item, $j ; C_{j}$ is the cost of a kilogram of food item, $j$; and $B_{i}$ and $K_{i}$ denote largest and smallest acceptable quantity of nutrient, $i$ respectively. Constraints in the model include the maximum amount of daily food consumption and the minimum and maximum nutritional requirements: energy, protein, carbohydrates, vitamin $\mathrm{A}$, vitamin $\mathrm{C}$, 
Table 1. Price and nutritional content of one kilogram of food items.

\begin{tabular}{lcccccccc}
\hline Food Item & $\begin{array}{c}\text { Price } \\
(\mathbf{U S ~} \mathbf{)})\end{array}$ & $\begin{array}{c}\text { Energy } \\
(\text { Kcal) }\end{array}$ & $\begin{array}{c}\text { Protein } \\
(\mathbf{g})\end{array}$ & $\begin{array}{c}\text { Carbohydrate } \\
(\mathbf{g})\end{array}$ & $\begin{array}{c}\text { Vitamin } \mathbf{A} \\
(\mathbf{m} \mathbf{c g})\end{array}$ & $\begin{array}{c}\text { Vitamin C } \\
(\mathbf{m g})\end{array}$ & $\begin{array}{c}\text { Iron } \\
(\mathbf{m g})\end{array}$ & $\begin{array}{c}\text { Calcium } \\
(\mathbf{m g})\end{array}$ \\
\hline Cassava & 0.12 & 1600 & 13.6 & 380.6 & 10 & 206 & 2.7 & 160 \\
Yam & 0.35 & 900 & 20.1 & 207.1 & 9610 & 196 & 6.9 & 380 \\
Plantains & 0.46 & 1160 & 7.9 & 311.5 & 450 & 109 & 5.8 & 20 \\
Maize & 0.29 & 970 & 33.4 & 217.1 & 0 & 62 & 5.5 & 20 \\
Tomato & 0.72 & 180 & 8.8 & 39.2 & 420 & 127 & 2.7 & 100 \\
Rice & 0.62 & 1120 & 23.2 & 235.1 & 0 & 0 & 5.3 & 100 \\
Oranges & 0.24 & 470 & 9.4 & 117.5 & 110 & 532 & 1 & 400 \\
Sorghum & 0.35 & 3390 & 113 & 746.3 & 0 & 0 & 44 & 280 \\
Coconut & 0.15 & 3540 & 33.3 & 152.3 & 0 & 33 & 24.3 & 140 \\
Milk & 0.28 & 610 & 31.5 & 48 & 460 & 0 & 0.3 & 1130 \\
Poultry meat & 2.84 & 2720 & 113.9 & 0 & 740 & 15 & 15.7 & 1380 \\
Cattle meat & 2.54 & 2540 & 171.7 & 0 & 0 & 0 & 19.4 & 180 \\
Porcine meat & 2.56 & 1280 & 210.6 & 0 & 20 & 0 & 8.7 & 130 \\
Constraints & & $\geq 2400$ & $\geq 56$ & $\geq 130$ & $900 \leq X \leq 3000$ & $90 \leq X \leq 2000$ & $8 \leq X \leq 45$ & $1000 \leq X \leq 2500$ \\
\hline
\end{tabular}

iron, and calcium. According to Anderson and Earle (1993), where only minimum requirements are set, there is a tendency for a linear programming application to have solutions showing a gross imbalance of some nutrients. The Food and Agriculture Organization (FAO) and the World Health Organization (WHO) model ensured that we prevented the problem of nutritional imbalance that is common in linear programming.

\section{Data}

The significant food items in the food balance sheet of Ghana and their producer prices were obtained from FAOSTAT. The producer prices were converted into U.S. dollars from the Ghanaian currency (Cedis). The minimum energy requirement (2400 calories) was obtained from US Department of Health and Human Services (HHS). The average age (22 years) was obtained from 2000 population census of Ghana (Ghana Districts, 2009) and the corresponding nutrition requirements from the US Department of Agriculture (USDA). Three kilogram was used as the maximum amount of food that an average Ghanaian can consume.

The daily minimum and maximum amounts of each required nutrient (Table 1) were obtained from HHS and the Dietary Reference Intake respectively. The nutritional value of each food item was obtained from the USDA nutrient data laboratory (USDA National Nutrient Database for Standard Reference).

\section{RESULTS}

According to the model, $\$ 0.36$ is the minimum per day amount that the average Ghanaian needs to spend on food to meet the necessary nutritional requirements. In order to achieve this minimum food expenditure, Table 2 (the 'level' column) shows that, the food basket must consist of $0.348 \mathrm{~kg}$ of cassava, $0.058 \mathrm{~kg}$ of yams, 0.173 $\mathrm{kg}$ of sorghum, $0.212 \mathrm{k} \mathrm{g}$ of coconuts and $0.747 \mathrm{~kg}$ of milk.

Table 2 (the 'marginal' column) further shows that although other food items like plantains, maize, tomatoes, have documented the harmful effects that may arise from excess consumption of some nutrients (FAO/WHO, 2003). Vitamin D and excess calcium are associated with kidney stone formation. High levels of vitamin A are associated with hair loss, bone pain and dry skin. Specifying upper and lower limits for each nutrient in our rice and oranges as well as some meat products (poultry, beef and pork) are widely produced and consumed in Ghana, their inclusion in the food basket will increase the minimum food expenditure. While consumption of a kilogram of plantains will increase food expenditure by $\$ 0.393$, consumption of tomatoes will increase it by $\$ 0.645$ per kilogram of tomatoes. For maize and rice, a kilogram consumption of each will increase food expenditure by $\$ 0.185$ and $\$ 0.541$, respectively. Quite insignificant is the $\$ 0.03$ that a kilogram of orange consumption adds to food expenditures. A kilogram consumption of any meat product: beef, pork or poultry would increase food expenditure by at least $\$ 2$. Needless to say, the consumption of any of the above food items will increase food expenditure because they are relatively more expensive than the components of the food basket suggested by the model.

As shown in Table 3, all the maximum constraints and the carbohydrate and iron minimum constraints are not binding in the model. The binding constraints in the model are minimum energy, protein, vitamins $A$ and $C$ and calcium requirements. According to Table 3, although these constraints are binding, a unit increase in the right hand side of any of them will not increase food expenditure significantly. A unit increase in the minimum energy, protein and calcium constraints will increase food expenditure by only \$0.000010750, \$0.002 and $\$ 0.00016504$, respectively. A unit increase in the right hand side of the minimum vitamins $A$ and $C$, on the other hand, will increase the food expenditure by $\$ 0.000019765$ and $\$ 0.0002121$, respectively. Tables 4 and 5 present the results of the sensitivity analysis. In 
Table 2. Optimal values of food items.

\begin{tabular}{lcccc}
\hline Food Item & Lower & Level & Upper & Marginal \\
\hline Cassava & 0 & 0.345 & $+\infty$ & 0 \\
Yam & 0 & 0.058 & $+\infty$ & 0 \\
Plantains & 0 & 0 & $+\infty$ & 0.393 \\
Maize & 0 & 0 & $+\infty$ & 0.185 \\
Tomato & 0 & 0 & $+\infty$ & 0.645 \\
Rice & 0 & 0 & $+\infty$ & 0.541 \\
Oranges & 0 & 0 & $+\infty$ & 0.03 \\
Sorghum & 0 & 0.173 & $+\infty$ & 0 \\
Coconut & 0 & 0.212 & $+\infty$ & 0 \\
Milk & 0 & 0.747 & $+\infty$ & 0 \\
Poultry meat & 0 & 0 & $+\infty$ & 2.296 \\
Cattle meat & 0 & 0 & $+\infty$ & 2.076 \\
Porcine meat & 0 & 0 & $+\infty$ & 2.029 \\
\hline
\end{tabular}

$+\infty$, Positive infinity.

Table 3. Optimal values of nutrient requirement.

\begin{tabular}{lcccc}
\hline Nutrient & Lower & Level & Upper & Marginal \\
\hline Energy & 2400 & 2400 & $+\infty$ & $1.08 \mathrm{E}-05$ \\
Protein & 56 & 56 & $+\infty$ & 0.002 \\
Carbohydrate & 130 & 341.47 & $+\infty$ & 0 \\
Vitamin A & 900 & 900 & $+\infty$ & $1.98 \mathrm{E}-05$ \\
Vitamin C & 90 & 90 & $+\infty$ & $2.12 \mathrm{E}-04$ \\
Iron & 8 & 14.307 & $+\infty$ & 0 \\
Calcium & 1000 & 1000 & $+\infty$ & $1.65 \mathrm{E}-04$ \\
\hline
\end{tabular}

$+\infty$, Positive infinity.

general there were small ranges for the optimal solution when considering the prices of the food items presented in Table 1. It would take a minimal altering of the price of a food item to cause the composition of the optimal food basket to change. A broader range was however observed for the nutrient requirements.

For all the binding constraints, assuming nondegeneracy, any change in their right hand side values ('current' column of Table 4), regardless of how small, will result in a change of the model's solution. The components of the food basket, and the marginal values of the food items, will however not change within the lower and upper limits ('lower' and 'upper' columns of Table 4) of each of the binding constraints.

If the price of a component of the food basket increases (decreases) by a small amount, the components of the food basket, and the solution, will remain unchanged while food expenditure will increase (decrease). If an increase in price is outside the lower and upper limits ('lower' and 'upper' columns of Table 5), the amount of that food item in the food basket will increase. However if the decrease is outside the range, the value of the food item will decrease. If the decrease is large enough the value will become zero (the components of the food basket will change)

Demand curves were developed for rice, cassava, and milk. As observed in Figure 1, these curves show the relative consumption of each food item that the model would advise given a change in price of the food item and keeping all other values constant. The graphs indicate that the quantity of milk suggested by the model is more sensitive to price changes than quantities of cassava and rice.

The model suggests a daily consumption of $0.747 \mathrm{~kg}$ of milk. With reference to the Ghanaian setting however, this figure is too high to be acceptable. We therefore constrained the maximum amount of milk that can be consumed to $0.5 \mathrm{~kg}$. This introduced oranges into, and cassava out, of the original food basket suggested by the model, and increased food expenditure by about $27.6 \%$. It also increased the total per day amount of food consumption by about $19 \%$; and increased the marginal values of the binding constraints and the food items that are not in the food basket. Further, the price of milk obtained from FAOSTAT seems quite low, so we increased it by $50 \%$ while maintaining the maximum milk consumption constraint. This affected the model in the same way as the maximum milk consumption alone did, except that the food expenditure increased by only $8.33 \%$ more than the original one suggested by the model. While maintaining the $50 \%$ increase in the price of milk, we decreased the maximum milk consumption constraint to $0.25 \mathrm{~kg}$. The effect of this on the model is similar to that of the $50 \%$ milk price increase plus the $0.5 \mathrm{~kg}$ maximum milk consumption constraint, except that the original food expenditure increased by about $65 \%$ and the amount of each food item, particularly oranges, in the food basket increased significantly. When the price of milk was increased by $50 \%$ without the maximum milk consumption constraint, the components of the original food basket suggested by the model did not change, but the food expenditure decreased by about $29 \%$; and the marginal values of the constraint and the food items that are not in the food basket changed. Next, we decided to do away with milk in the model. When this was done, the original food expenditure increased by about $84 \%$ and orange was introduced into the original food basket. The daily consumption of oranges suggested by the model when milk was taken of the model is about $2.2 \mathrm{~kg}$, which is significantly higher than the other food items in the food basket. After this change any further manipulation of the model resulted in unrealistic objective function values.

\section{DISCUSSION AND CONCLUSION}

The model simulation for the least cost diet determined that an average Ghanaian can spend $\$ 0.36$ per day on his nutritional requirements. The optimal solution is low because the average Ghanaian produces his own food and buys only the food items that he does not produce. 
Table 4. Nutrient constraint sensitivity.

\begin{tabular}{lccc}
\hline Equation name & Lower & Current & Upper \\
\hline Minimum energy requirement & 1900 & 2400 & 3935 \\
Minimum protein requirement & 42.67 & 56 & 72.28 \\
Minimum carbohydrate requirement & $-\infty$ & 130 & 341.5 \\
Minimum vitamin A requirement & 353.4 & 900 & 3000 \\
Minimum vitamin C requirement & 23.56 & 90 & 173.8 \\
Minimum iron requirement & $-\infty$ & 8 & 14.31 \\
Minimum calcium requirement & 217.9 & 1000 & 1583 \\
Maximum energy requirement & 2400 & 1000000 & $+\infty$ \\
Maximum protein requirement & 56 & 1000000 & $+\infty$ \\
Maximum carbohydrate requirement & 341.5 & 1000000 & $+\infty$ \\
Maximum vitamin A requirement & 900 & 3000 & $+\infty$ \\
Maximum vitamin C requirement & 90 & 2000 & $+\infty$ \\
Maximum iron requirement & 14.31 & 45 & $+\infty$ \\
Maximum calcium requirement & 1000 & 2500 & $+\infty$ \\
Maximum food consumption & 1.538 & 3 & $+\infty$ \\
\hline
\end{tabular}

$"+\infty$, Positive infinity; $-\infty$, negative infinity.

Table 5. Food item sensitivity analysis.

\begin{tabular}{lccc}
\hline Food Item & Lower & Current & Upper \\
\hline Cassava & 0.07924 & 0.1197 & 0.1306 \\
Yam & 0.1637 & 0.3515 & 3.958 \\
Plantain & 0.06649 & 0.4599 & $+\infty$ \\
Maize & 0.106 & 0.2907 & $+\infty$ \\
Tomato & 0.07451 & 0.72 & $+\infty$ \\
Rice & 0.08348 & 0.6241 & $+\infty$ \\
Orange & 0.2083 & 0.2386 & $+\infty$ \\
Sorghum & 0.1675 & 0.3502 & 0.4458 \\
Coconut & 0.1222 & 0.147 & 0.231 \\
Milk & 0.104 & 0.2767 & 0.6115 \\
Poultry meat & 0.5445 & 2.841 & $+\infty$ \\
Bovine meat & 0.4636 & 2.539 & $+\infty$ \\
Porcine meat & 0.5343 & 2.564 & $+\infty$ \\
\hline
\end{tabular}

$+\infty$, Positive infinity.

The $\$ 0.36$ represents $19 \%$ of an average Ghanaian's daily income of $\$ 1.89$ (World Bank, 2008), and is significantly smaller than the 60 to $70 \%$ of daily income that is spent on food in developing countries. Therefore, if the findings of this model are adhered to, the average Ghanaian will be able to curtail food expenditure by about $40 \%$ and have enough of his income (about $80 \%$ ) left for other financial obligations. Thus, all things being equal, human livelihood and poverty can be improved in Ghana if the results of this study are adhered to.

To satisfy his/her nutritional requirement while minimizing costs, an average Ghanaian should consume sorghum, yams, cassava, coconuts and milk. Cassava, yam, sorghum and coconuts are produced in many parts
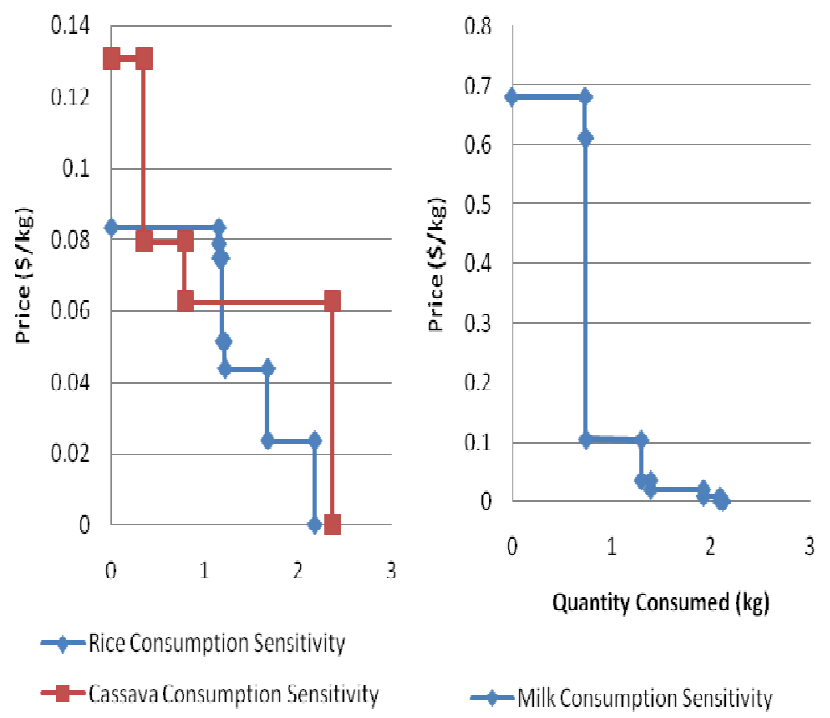

Figure 1. Sensitivity of rice, cassava, and milk to price variation.

of Ghana, and thus readily available and frequently consumed by many people - both rich and poor. Although milk is produced in high quantities, unlike the other food items, because it is relatively more expensive, milk is not a common food item in the food basket of poor households especially. In order to encourage the consumption of milk by poor households, milk has to be reasonably priced. This can be done through a milk production subsidy program and/or a milk price control program. Notwithstanding the difference in the components of food basket across the various zones of 
the country, the food basket recommended by this study is adoptable. The difference in the components of the food basket across zones is more of a matter of availability and food expenditure than it is of culture since the staple food of many cultural groups are made from about the same food items. But for milk, the food items recommended by this study are widely available in all parts of the country, and per the results of this study, the food items can be obtain at a minimum cost.

The minimum constraints on energy, protein, vitamin A, vitamin $C$ and calcium are binding in the model. If the recommendations of this model are adhered to, the marginal values of the binding minimum constraints show that the nutrient intake of a Ghanaian can be increased without any significant effect on food expenditure. Assuming non-degeneracy for all the binding constraints, any change in their right hand side values will result in a change of the model's solution. The components of the food basket will however not change within the lower and upper limits of each of the binding constraints. Note that the marginal values of the food items will also remain constant within the specified range. If the price of a component of the food basket increases (decreases) by a small amount, the components of the food basket, and the solution, will remain unchanged while food expenditure increases (decreases). If an increase in price is outside the lower and upper limits the amount of that food item in the food basket will change.

Stigler (1945), Smith (1959), Foytik (1981) and Colavita D'Orsi (1990) used models similar to the one used in this study to formulate normative diets for poor households, and for young and elderly population groups. These studies (including ours), implicitly assume that the nutritional requirements are independent, all nutrients are equally important, and that all sources of nutrients are equivalent. These assumptions are however not very realistic in that nutritional requirements are not independent, and it is common knowledge that some nutrients are more important than others. In view of this, some contemporary studies (Conforti and D'Amicis, 2000; Briend et al., 2003) include, or advocate the inclusion of additional constraints derived from observed habits and behaviors to limit the amount of some food items in the solution. Conforti and D'Amicis (2000), for instance, constrained the amount of each food item that enters the solution to equal a given proportion of the food group (for example, meat, vegetable etc.) to which the food item belongs; and the various food group are in turn constrained to equal specific proportions of the total food in the solution.

Although the underlying assumptions of this study are not very realistic, given the many cultural groups in Ghana, and the fact that different cultural groups consume food items and food groups in different proportions, it will be impractical to impose constraints like those of Conforti and D'Amicis (2000). The results of the study are therefore considered to be for Ghana in general and not for any specific cultural group. Future studies can consider the food consumption patterns of specific cultural groups, and impose relevant constraints. Despite the general nature of the results, important implications regarding malnutrition in Ghana can be drawn, because like the results of any linear programming diet model, it provides a stylized description (not a normative tool) of the diet of the average Ghanaian. Policy makers who desire to diminish the impacts of malnutrition can focus efforts on price stabilization and subsidization of a few key foods determined by the model. Milk is especially important contributing more than half of the cost minimizing consumption bundle.

An important limitation of the study is our use of producer prices, instead of retail prices, of the food items, and the implications that this would have on the results. Food and Agriculture Organization database had only producer prices. Meanwhile, producer prices do not necessarily present any problem where individuals consume their own produce as it would have cost them exactly the (producer) price to buy it. Problems however arise when an individual has to buy a food item that is not widely grown in his/her region. If such a food item comes from a different region then it has to be purchased at the retail price. Taking this into consideration the food budget and the composition of our food basket would change.

\section{ACKNOWLEDGEMENT}

Presentation of this research was made possible, in part, through support provided by the Bill and Belinda Gates Foundation, and the Bureau of Economic Growth, Agriculture and Trade, U.S. Agency for International Development through the BASIS Assets and Market Access Collaborative Research Support Program. The opinions expressed herein are those of the authors and do not necessarily reflect the views of the sponsoring agency

\section{REFERENCES}

Alderman H (1990). Nutritional status in Ghana and its determinants. Social Dimensions of Adjustments in sub-Saharan Africa. World Bank Working Paper nr 3. World Bank, Washington.

Anderson AM, Earle MD (1993). Diet Planning in the Third World by Linear and Goal Programming. J. Operat. Res. Soc. 34: 9-16.

Briend A, Darmon NF, urguson E, Erhardt JE (2003). Linear Programming: A mathematical Tool for Analyzing and Optimizing Children's Diets During the Contemporary Feeding Period. J. Ped. Gastroel. Nutr. 36:12-22.

CIA statistics. Central Intelligence Agency WORLD FACTBOOK.Available at www.cia.gov/library/publications/the-worldfactbook/rankorder/2224rank.html.Accessed on December, 2012.

Colavita C, D'Orsi R (1990). Linear programming and paediatric dietetics. Br. J. Nutr. 64:307-17.

Conforti P, D'Amicis A (2000). What is the cost of a healthy diet in terms of achieving RDAs? Public Health Nutrition: 3(3), 367-373.

Darmon N, Ferguson E, Briend A (2002). A Cost Constraint Alone Has Adverse Effects on Food Selection And Nutrient Density: An Analysis of Human Diets by Linear Programming. J. Nutr. 64:3771. 
FAOSTAT. Food and Agriculture Organization Statistical database. Available at www.faostat.fao.org. Accessed on November 20, 2009.

FAO/WHO Expert Group (2003). Requirement of Ascorbic Acid, Vitamin D, Vitamin. B12, Folate and Iron. Food and Agriculture Organization.

Ferguson EL, Darmon N, Andre B, Emachandral M (2003). Food-Based Dietary Guidelines can be Developed and Tested Using Linear Programming Analysis.Am. Soc. NutritionalSci. pp.951-957

Foytik J (1981). Very low-cost nutritious diet plans designed bylinear programming. J. Nutr. Educ., 13: 63-6.

Garille SG, Gass IS (2001). Stigler's Diet Problem Revisited. Operat. Res. 49:1-13

Ghana Districts. Available at www.ghanadistricts.com/districts.Accessed November 29, 2009.

Lancaster LM (1992). The Evolution of the Diet Model in Managing Food Systems. Interfaces 5:59-68

Muller O, Krawinkel M (2005). Malnutrition and Health in Developing Countries. Can. Med. Assoc. J. 173: 279-286.

Smith VF (1959). Linear programming models for the determination of palatable human diets. J. Farm Econ., 31:56-72.
Smith L, Haddad L. (2000). ExplainingChild Malnutrition in Developing Countries:A Cross Country Analysis. International Food Policy Research Institute, Washington DC, Research Report. p.111.

Stigler GJ (1945). The Cost of Subsistence. J. Farm Econ. 27:303-314

World Bank (2008).World Development Indicators (WDI).Available at www.worldbank.org.Accessed on November 29, 2009.

Ziraba AK, Fotso JC, Ochako R (2009). Overweight and obesity in urban Africa: A problem of the rich or the poor? BMC Public Health. 